\title{
Polymyxa graminis Isolates from Australia: Identification in Wheat Roots and Soil, Molecular Characterization, and Wide Genetic Diversity
}

B. A. Cox, Crop Protection Branch, Department of Agriculture and Food Western Australia, Locked Bag No. 4, Bentley Delivery Centre, Perth, WA 6983, Australia, and School of Plant Biology and Institute of Agriculture, Faculty of Science, University of Western Australia, 35 Stirling Highway, Crawley, WA, 6009, Australia; H. Luo, Crop Protection Branch, Department of Agriculture and Food Western Australia, Perth, WA 6983, Australia; and R. A. C. Jones, Crop Protection Branch, Department of Agriculture and Food Western Australia, and School of Plant Biology and Institute of Agriculture, Faculty of Science, University of Western Australia

\begin{abstract}
Cox, B. A., Luo, H., and Jones, R. A. C. 2014. Polymyxa graminis isolates from Australia: Identification in wheat roots and soil, molecular characterization, and wide genetic diversity. Plant Dis. 98:1567-1575.

Polymyxa graminis is an obligate parasite of roots and an important vector of viruses that damage cereal crops in different parts of the world. In 2011 and 2012, P. graminis was identified infecting 11 wheat root samples from three widely dispersed locations in southwest Australia. Its presence was detected by polymerase chain reaction (PCR) and confirmed by DNA sequencing of the transcribed regions of its ribosomal RNA genes (rDNA) and observing sporosori of characteristic morphology and size in stained wheat roots. Also, when soil samples were collected from two locations where P. graminis was found and wheat bait plants grown in them, $P$. graminis was detected in their roots by PCR. Ribosomal DNA sequences of six southwest Australian isolates were obtained from wheat roots, and one northeast Australian isolate from barley roots. When these seven $P$. graminis sequences were compared with others from GenBank by phylogenetic analysis, three southwest Australian isolates were classified as P. graminis f. sp. temperata (ribotypes Ia and Ib), and three as f. sp. tepida (ribotypes IIa and $\mathrm{IIb})$. P. graminis f. sp. temperata and tepida both occur in

temperate growing regions of other continents and are associated with transmission of soil-borne viruses to cereal crops. The $P$. graminis isolate from northeast Australia was sufficiently distinct from the five existing sequence groups for it to be placed into a newly proposed grouping, ribotype VI, which also included an isolate from tropical West Africa. However, when randomly collected wheat leaf samples from 39 field crops from 27 widely dispersed locations, 21 individual wheat plant samples collected from low lying areas within 21 fields at 11 locations, and wheat bait plants growing in five soil samples from two locations were tested by reverse transcription (RT)-PCR for the presence of Soil-borne wheat mosaic virus, Soil-borne cereal mosaic virus, Wheat spindle streak mosaic virus, and furoviruses in general, no virus infection was detected. These findings suggest at least three $P$. graminis introductions into Australia, and the occurrence of f. sp. temperata (ribotype I) and f. sp. tepida (ribotype II) suggests that, if not already present, soil-borne cereal viruses are likely to become established should they become introduced to the continent in the future.
\end{abstract}

Plasmodiophorids were traditionally considered to be fungi until phylogenetic analysis of their small subunit ribosomal DNA sequences classified them within the protists $(6,10)$. The plasmodiophorid virus vector genus Polymyxa is most closely related to Ligniera and Sorosphaera, and more distantly to Plasmodiophora and the virus vector genus Spongospora (36). The two species of Polymyxa that act as virus vectors, $P$. graminis and $P$. betae, were formerly distinguished largely on the basis of host range, as they are morphologically very similar. $P$. graminis mainly infects cereals and grasses, while P. betae mainly infects Chenopodiaceae (4). However, their ribosomal DNA sequences are now known to distinguish them $(30,36,37)$.

$P$. graminis is an obligate biotrophic parasite of plant roots $(13,17)$. It has a biphasic life cycle, with (i) a sporogenic phase resulting in production of sporosori containing resting spores which produce primary zoospores, and (ii) a sporangial phase, resulting in production of zoosporangia which produce secondary zoospores $(5,13)$. Each phase is initiated by the attachment of zoospores and penetration of epidermal or root hair cells. Secondary

Corresponding author: R. A. C. Jones,

E-mail: roger.jones@agric.wa.gov.au

* The $e$-Xtra logo stands for "electronic extra" and indicates that a supplementary table is available online, and that Figure 5 appears in color online.

Accepted for publication 10 May 2014.

http://dx.doi.org/10.1094/PDIS-02-14-0128-RE

(C) 2014 The American Phytopathological Society zoospores have the ability to initiate either phase of the cycle. Molecular diversity and phylogeny of $P$. graminis isolates were studied using restriction fragment length polymorphisms (RFLPs) and sequencing of transcribed regions of ribosomal RNA genes $(18,24,36,37)$. A high level of sequence diversity occurs between $P$. graminis isolates, with $>20 \%$ differences across the $18 \mathrm{~S}, 5.8 \mathrm{~S}$, and internal transcribed spacer rDNA regions. Several rDNA subgroups (ribotypes) of $P$. graminis occur $(18,21,22,36,38)$. Biological and molecular studies revealed differences in host range, temperature requirements, and genome characteristics, leading to the proposal to divide $P$. graminis into five forma speciales (ribotype designations in parentheses): f. sp. temperata (I), tepida (II), tropicalis (III), subtropicalis (IV), and colombiana (V) (18). P. graminis $\mathrm{f}$. sp. temperata and tepida occur in cereal crops in temperate regions multiplying best at temperatures of 15 to $20^{\circ} \mathrm{C}$, whereas isolates belonging to the other three forma speciales preferred higher growth temperatures (21). An additional temperate ribotype (VI) was proposed subsequently (39), but later placed within f. sp. tep$i d a$ (ribotype IIb) (30). Whether temperate, tropical, and subtropical ribotypes can be distinguished based on host specificity or host preference remains unclear $(22,23,30,34)$. For example, in one study, temperata was found more frequently on barley, and tepida on wheat, but different ribotypes often occurred together in the same soil or plant (34).

$P$. graminis is not considered a plant pathogen in its own right, but poses a significant threat to agriculture because of its ability to transmit agronomically important viruses that cause severe diseases in several major crop species. These crop hosts include wheat, barley, oats, pearl millet, rice, rye, and sorghum $(1,22)$. $P$. graminis is a vector of at least 14 different soil-borne plant viruses belonging to the genera Furovirus, Bymovirus, Pecluvirus, and Benyvirus. Soil-borne viruses it transmits that infect wheat include: 
the furoviruses Soil-borne wheat mosaic virus (SBWMV), Soilborne cereal mosaic virus (SBCMV), and Chinese wheat mosaic virus (CWMV), and the bymoviruses Wheat spindle streak mosaic virus (WSSMV) and Wheat yellow mosaic virus (WYMV), and Aubian wheat mosaic virus (genus unassigned). These viruses occur in parts of Europe, Asia, and North America, and SBWMV in New Zealand $(13,15,16)$. In addition, two pecluviruses it transmits, Indian peanut clump virus (IPCV) and Peanut clump virus (PCV), occur in the Indian subcontinent and Africa, respectively. IPCV and PCV sometimes cause damaging diseases of wheat growing under subtropical conditions (11,31). Different soil-borne viruses have been associated with distinct types of $P$. graminis. Temperate f. sp. temperata (ribotype I) and f. sp. tepida (ribotype II) are associated with WSSMV, SBCMV, SBWMV, Barley yellow mosaic virus (BaYMV), and Barley mild mosaic virus (BaMMV) infection in cereal crops $(16,30,37)$. P. graminis f. sp. tropicalis (ribotype III) and f. sp. subtropicalis (ribotype IV) are associated with pecluviruses $(18,22)$, and f. sp. colombiana (ribotype $\mathrm{V}$ ) with Rice stripe necrosis virus (RSNV) (24). Viruses can be present in $P$. graminis during all stages of its life cycle and can persist inside its thickwalled resting spores, remaining viable in the soil for decades. Virus is acquired and transmitted either when zoospores penetrate host cells and transfer their contents into the cytoplasm, or at the young plasmodium stage when only a thin membrane boundary separates cytoplasm of $P$. graminis from that of its host (5,31).

In Australia, P. graminis was detected in 2009 in the roots of a barley crop in Wondai, Queensland, in subtropical northeast Australia, and was identified as $P$. graminis f. sp. tepida according to polymerase chain reaction (PCR) results (33). The only other record of $P$. graminis in Australia was an unconfirmed observation of its sporosori in Poа апnиa roots in 1959 in Murrumburra, which has a warm temperate climate and is in southeast New South Wales, central eastern Australia (3). No soil-borne viruses of cereal crops have been recorded in Australia (12). Southwest Australia, which has a Mediterranean type climate, hosts an extensive grainbelt which is the biggest wheat producing area in Australia. Cereals are sown in the grainbelt in late autumn or early winter and harvested in late spring, and are entirely rainfed, with the majority of the annual rainfall occurring between late fall (autumn) and early spring (May to September). The amount of rainfall is greatest near to the coast (high rainfall zone) and least further inland (low rainfall zone). Fields are large (up to 250 ha in size), and the cultural practices used are low input (minimum tillage and retained stubble) with wheat being grown continuously or in rotation with canola, grain legumes (field pea or lupin) or annual legume pastures.

This paper reports the detection in 2011 and 2012 of $P$. graminis in the roots of wheat plants sampled at three locations in southwest
Australia. It was also detected in the roots of wheat bait plants grown in soil samples from two of these locations. Identification of $P$. graminis was confirmed by PCR, microscopic observation of sporosori in stained roots, and characterization of isolates by sequencing of transcribed regions of ribosomal DNA. Phylogenetic analysis of $P$. graminis of six isolates from southwest and one isolate from northeast Australia revealed presence of f. sp. temperata (ribotype I), f. sp. tepida (ribotype II), and a new sequence group proposed in this study, ribotype VI.

\section{Materials and Methods}

Plant and soil collection. During September and October in 2011 and September in 2012, 100 leaf samples were collected for virus testing from each of 39 wheat crops growing in the southwest Australian grainbelt (Fig. 1). This leaf sampling involved 20 crops at 13 different locations in 2011 and 19 crops at 14 locations in 2012 (Supplementary Table 1). These locations were at widely dispersed sites, ranging from Geraldton in the northern grainbelt to Esperance in the south coastal grainbelt (a distance of $896 \mathrm{~km}$ ) in 2011, and from Perth to Esperance (a distance of $740 \mathrm{~km}$ ) in 2012. The 100 samples/crop were all taken at random by walking though the crop in a W-shaped pattern and sampling a leaf every $5 \mathrm{~m}$. No potentially symptomatic plants were sampled or present. In addition, whole wheat plant samples with roots were collected from low lying areas within 21 fields. These fields were at Esperance (4 locations, 12 samples) and Pingelly (1 location, 1 sample) in 2011, and Northam (2 locations, 2 samples), Kulin (3 locations, 3 samples), and Department of Agriculture and Food (DAFWA) irrigated field plots in South Perth (2 plots, 3 samples) in 2012 (Fig. 1). Five soil samples were also collected in the immediate vicinity of plant samples at Esperance (3 samples) in 2011 and South Perth (2 samples) in 2012. Dried barley root samples obtained from Wondai, Queensland and known to be infected with P. graminis (33) were kindly provided by J. M. Thompson and K. J. Owen. These were used as positive controls for PCR tests.

DNA extraction and PCR. Roots were washed in tap water to remove soil and dried on paper towels. A subsample of approximately $1 \mathrm{~g}$ of root material was ground to a fine powder under liquid nitrogen using a mortar and pestle. DNA was extracted from $80 \mathrm{mg}$ of ground root powder using a DNeasy Plant Mini kit (Qiagen) as per manufacturer's instructions. DNA was diluted 1:10 with RNase-free water prior to PCR. PCRs were done using Polymyxa spp. primer pair Pxfwd1/Pxrev7 and P. graminis primer pair Pgfwd2/Pxrev7 (36). Each 20- $\mu$ l reaction mixture contained $1 \mu \mathrm{l}$ of diluted DNA, $1 \times$ PCR buffer, $1.5 \mathrm{mM} \mathrm{MgCl} 2,0.2 \mathrm{mM}$ dNTPs, 0.5 $\mu \mathrm{M}$ each primer, and $0.5 \mathrm{U}$ Taq polymerase (Qiagen). PCR cycling conditions were $94^{\circ} \mathrm{C}$ for $3 \mathrm{~min}$, followed by 35 cycles of $94^{\circ} \mathrm{C}$ for

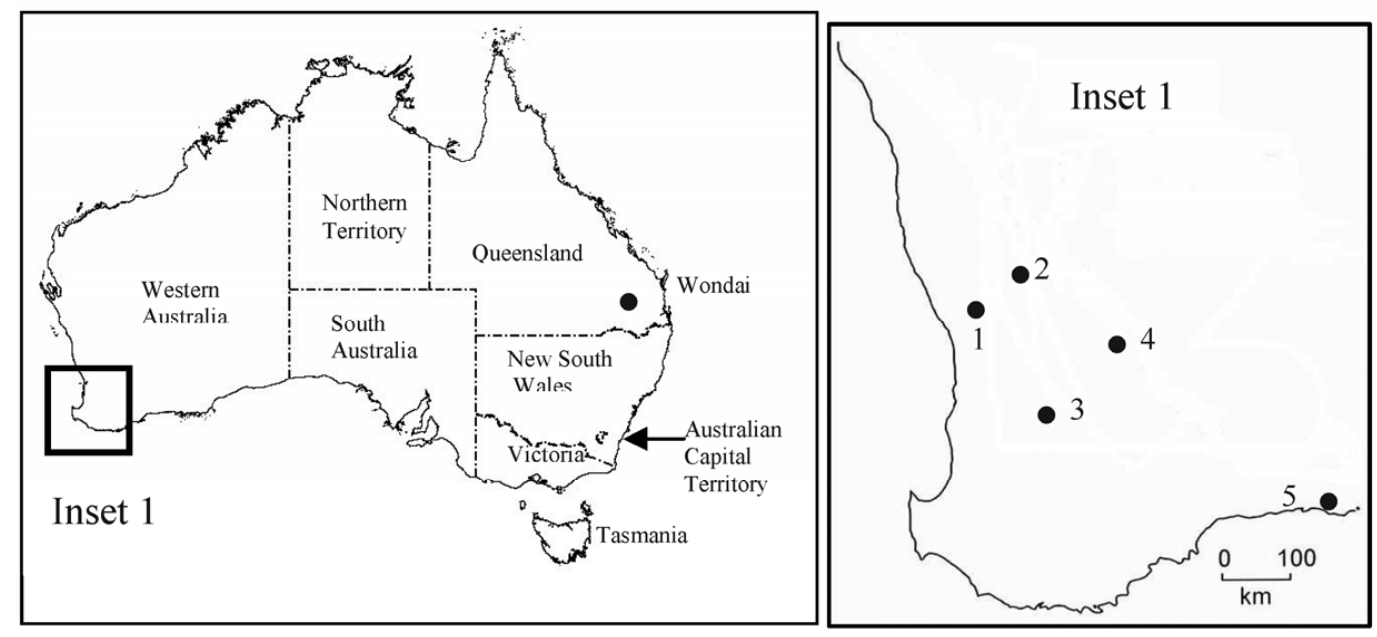

Fig. 1. Map of Australia showing locations where 21 whole wheat plant samples were collected from low lying areas within fields to test their roots for presence of Polymyxa graminis. Numbered dots represent locations sampled: 1. South Perth; 2. Northam; 3. Pingelly; 4. Kulin; 5. Esperance. P. graminis was detected at three of these locations (numbers of positive samples in parentheses): South Perth (3), Northam (2), Esperance (6). 
$30 \mathrm{~s}, 56^{\circ} \mathrm{C}$ for $1 \mathrm{~min}, 72^{\circ} \mathrm{C}$ for $1 \mathrm{~min}$, with a final extension at $72{ }^{\circ} \mathrm{C}$ for $10 \mathrm{~min}$. Products were analyzed on a $2 \%$ agarose gel in TAE buffer and stained with ethidium bromide.

RNA extraction and reverse transcription (RT)-PCR. Root samples ( $80 \mathrm{mg} / \mathrm{sample}$ ) ground under liquid nitrogen as described above for DNA extraction were also used for RNA extraction. For 100 leaf samples, 1-cm-long leaf pieces were subsampled from each leaf and pooled for one extraction. With individual plant samples, five leaves from each plant were pooled. Pooled leaf samples were ground to a fine powder under liquid nitrogen in a mortar and pestle, and RNA extractions carried out on $100 \mathrm{mg}$ of ground leaf material using a Spectrum Plant Total RNA kit (Sigma) as per manufacturer's instructions. Leaves and roots were tested for the presence of soil-borne viruses by RT-PCR, using a OneStep RTPCR kit (Qiagen), as per manufacturers' instructions, with specific primer pairs WSSMVc2F/WSSMVc2R for WSSMV (35), SBWMV-EF/SBWMV-UNIR for SBCMV (8), SBMV L2/SBMV R2 for SBWMV (9), and universal primers Furo1-F/Furo2-F for furoviruses (28). Virus-infected dried leaf samples of each virus obtained from DSMZ (Germany) were used as positive controls.

Sequencing and phylogenetic analysis. To obtain ITS region sequences from root samples containing Polymyxa spp., PCR was done on root DNA extractions using primer pairs Psp1/Psp2rev (20), Psp1/ITS 4 (40), and Pgf2/ITS4 (37). Amplicons were purified using QIAquick PCR purification kit (Qiagen) where one band was present. When multiple bands were present, they were separated by agarose gel electrophoresis and purified using QIAquick Gel extraction kit (Qiagen). Both strands of PCR products were sequenced directly with the primers used for amplification in an AB 3730 DNA Analyzer using Big Dye v 3.1 Terminator chemistry (Applied Biosystems, Victoria, Australia). Overlapping sequences were aligned and edited using Geneious v 6, and submitted to the GenBank database. Nucleotide (nt) sequence data for 46 $P$. graminis rDNA-ITS region sequences from GenBank that included the complete ITS 1, 5.8S rRNA gene, and ITS 2 were aligned in Mega v 5 using ClustalW, and manually edited. Lengths of sequences ranged from 411 to 485 bases. A P. betae sequence was included in the alignment as an outgroup. Phylogenetic analysis was carried out in Mega v 5 (32) using the neighbor-joining method. The alignment and analysis was then repeated, with sequences trimmed to the end of the 5.8S gene, so that an extra 16 sequences with partial coverage of the ITS region could be included. Sequence lengths ranged from 257 to 310 bases.
Microscopy. A 0.5-g subsample of washed dried roots (sample Northam P5) was cleared and stained with trypan blue (26). Root pieces were mounted in lactic acid on microscope slides and observed under a compound microscope at magnifications up to $\times 400$. Photomicrographs of $P$. graminis sporosori were taken with an Olympus UC30 microscope/camera system.

Soil bait tests. Soil collected from South Perth (samples SP22 and SP28) and Esperance (samples GG, E2, and W12), was spread out on newspaper to air dry. The dried soil samples were diluted with sterile sand at a $1: 3 \mathrm{vol} / \mathrm{vol}$ ratio and added to clean $18-\mathrm{cm}-$ diameter pots, one pot per soil sample. Sterile potting mix containing sand was used as a control. Wheat seeds (cv. Calingiri) were surface sterilized with $2.5 \% \mathrm{NaClO}$ and planted into pots, four seeds per pot. Pots were placed on a free-draining metal grill in a growth cabinet, $16^{\circ} \mathrm{C}$ night and $20^{\circ} \mathrm{C}$ day with a 12 -h photoperiod, and watered daily. After 2 months, pot contents were removed and roots of individual plants were washed free of all soil and sampled for DNA and RNA extraction. Leaves were sampled for RNA extraction. PCR assays (for root extracts) and RT-PCR assays (for leaf extracts) were used to test the samples as described above.

\section{Results}

PCR testing of field samples. Polymyxa spp. were detected by PCR using the Polymyxa spp. primer pair Pxfwd1/Pxrev7 in DNA extracted from 14 out of 21 wheat root samples from Esperance (9 samples), South Perth (3 samples), Northam (1 sample), and Kulin (1 sample) (Table 1). Eleven samples gave a band with $P$. graminis type I and II specific primer pair Pgfwd2/Pxrev7, including one which gave no band with primer pair Pxfwd1/Pxrev7. The approximate size of the PCR products for the three samples from South Perth (290 bp) corresponded to the published size for $P$. graminis type I (36), and one of these samples produced two bands (290/230 bp) with primer pair Pgfwd2/Pxrev7, indicating ribotypes I and II were both present (Fig. 2). Five samples from Esperance gave a smaller band (approx. 290 bp) with Polymyxa spp. primer pair Pgfwd1/Pxrev7 corresponding to ribotype I, and a larger band (320 $\mathrm{bp}$ ), corresponding to ribotype II with primer pair Pgfwd2/Pxrev7. One sample each from Esperance and Northam also produced a second PCR band with primer pair Pgfwd1/Pxrev7, indicating the presence of ribotypes I and II. One sample from Kulin and three from Esperance gave a 290-bp band with primer pair Pgfwd1/Pxrev7, but no band with the ribotype I and II primer pair Pgfwd2/Pxrev7. This corresponds most closely to a ribotype III

Table 1. Polymyxa spp. polymerase chain reaction (PCR) product sizes obtained from wheat root field samples

\begin{tabular}{|c|c|c|c|c|}
\hline \multirow[b]{2}{*}{ Sample ID } & \multirow[b]{2}{*}{ Location } & \multirow[b]{2}{*}{ Cultivar } & \multicolumn{2}{|c|}{ PCR product size (bp) with Polymyxa spp. primer sets } \\
\hline & & & Pxfwd1/Pxrev7 & Pgfwd2/Pxrev7 \\
\hline E2 & Esperance & Sapphire & 290 & 320 \\
\hline E2-1 & Esperance & Sapphire & $\ldots$ & $\ldots$ \\
\hline E2-2 & Esperance & Sapphire & 290 & 320 \\
\hline E2-3 & Esperance & Sapphire & 290 & $\ldots$ \\
\hline W12 & Esperance & Sapphire & 290 & 320 \\
\hline W12-1 & Esperance & Sapphire & $290 / 320$ & 320 \\
\hline W12-2 & Esperance & Sapphire & 290 & \\
\hline W12-3 & Esperance & Sapphire & 290 & 320 \\
\hline GG & Esperance & Unknown & 290 & 320 \\
\hline GG-1 & Esperance & Unknown & $\ldots$ & $\ldots$ \\
\hline GG-2 & Esperance & Unknown & 290 & $\ldots$ \\
\hline TOS & Esperance & Sapphire & $\ldots$ & $\ldots$ \\
\hline Pingelly & Pingelly & Unknown & $\cdots$ & $\cdots$ \\
\hline SP 22a & South Perth & Unknown & 290 & 290 \\
\hline SP $22 b$ & South Perth & Unknown & 290 & $290 / 320$ \\
\hline SP 28 & South Perth & Unknown & 290 & 290 \\
\hline $\mathrm{KE}$ & Kulin & Mace & $\ldots$ & $\ldots$ \\
\hline KW & Kulin & Mace & $\ldots$ & $\ldots$ \\
\hline KWH & Kulin & Mace & 290 & $\ldots$ \\
\hline P38 & Northam & Magenta & & 290 \\
\hline P5 & Northam & Benu & $320 / 290$ & 320 \\
\hline Qld control & Wondai & Dictator (barley) & 330 & 330 \\
\hline
\end{tabular}

${ }^{a}$ From Ward and Adams (36). 
result. One sample from Northam produced a 290-bp band with primer pair Pgfwd2/Pxrev7, but no band with primer pair Pgfwd1/Pxrev7, indicating ribotype I presence. RT-PCR tests on the roots or leaves of the 21 individual field plant samples, or 100 leaf samples taken at random from 39 wheat crops, did not detect WSSMV, SBCMV, SBWMV, or with the generic furovirus primer pair, any other soil-borne virus.

DNA sequencing. Wheat field sample extracts in which $P$. graminis was detected by PCR were amplified for sequencing using three sets of primers in order to obtain complete ITS region sequences. Seven new $P$. graminis sequences were obtained, three from the Northam, two from the South Perth, and one each from Esperance and Queensland samples (Table 2). Considerable sequence variation was found within the Australian isolates sequenced, their nt sequence identities ranging from 73.9 to $100 \%$. Two distinct isolates were obtained from South Perth samples, one with $99.6 \%$ nt identity with $P$. graminis ribotype II isolate 'Kent' from wheat in the UK, the other whose sequence was identical to a ribotype I isolate 'Ag' from Switzerland (see Table 3 for full list of isolates compared). The sequence obtained from Esperance most closely resembled that of isolate 'garden' from the UK $(99.7 \%$ identity). Three sequences were obtained from the Northam samples, one of which was identical to the Esperance sequence. The other two shared closest nt identities (97.9 to 99.8\%) with ribotype I isolates 'C13SH' and 'Oto4' from Belgium. Five barley root samples from Queensland were sequenced, and all had an identical $P$. graminis sequence, which had $99.9 \%$ identity with sorghum isolate 'BF-209' from Burkina Faso. A second PCR band was also produced from Queensland barley samples with primers Psp1/Psp2rev and sequenced, but it was more closely related to $P$. betae sequences. In addition, partial sequences were obtained from a sample from Kulin, and one from Esperance. These two partial sequences shared some homology with other $P$. graminis sequences, but not enough sequence information was obtained to identify them.

Phylogenetic analysis. The tree generated using $P$. graminis sequences that included all of the ITS 1 and 2 regions revealed great sequence diversity. The complete set of isolates compared (Table 3) grouped into six distinct clades with strong bootstrap support, corresponding to the five previously recognized ribotypes, and one new clade (Fig. 3). There was sufficient diversity within clades I and II for separation of both into two smaller subclades, $a$ and $b$. Northeast Australian isolate QldB was placed into a new clade which contained only isolate BF-209 from Burkina Faso in West Africa. This clade was closest to clade V, which contained one isolate each from South America and Africa, but was distant enough and with reasonable bootstrap support to be considered a separate clade, clade VI. One South Perth isolate was located with three European isolates in subclade Ib, and the other South Perth isolate grouped with six European isolates in subclade IIa. Clade III contained eight isolates from the United States, Africa, and India, while clade IV consisted of two isolates from India and one from Pakistan.

When the phylogenetic analysis was repeated with sequences trimmed to ITS 1 and $5.8 \mathrm{~S}$ gene only such that isolates without ITS 2 could be included, another tree with six major clades was produced (Fig. 4). Isolates with complete ITS region sequences were all within the same clades as previously. However, clades III, V, and VI changed positions in this phylogenetic tree due to use of shorter lengths and greater numbers of sequences. Northam isolate P38 was in subclade Ia with isolates from North America and Europe, and isolate NorP5S was in subclade Ib with SP1. The remaining Northam isolate NorP5B, and Esperance isolate EspW12B were located in subclade IIb with an isolate from the UK.

Observation of $\boldsymbol{P}$. graminis in wheat roots. Photomicrographs of $P$. graminis observed in stained sections of wheat roots from Northam (sample P5) are shown in Figure 5A and B. Multiple sporosori were observed, their appearance corresponding to descriptions of $P$. graminis sporosori in wheat given by Ledingham (17) and Barr (4). Individual resting spores were approximately 4 $\mu \mathrm{M}$ in diameter.

Soil bait tests. Polymyxa spp. and $P$. graminis ribotypes I and II were detected by PCR in the roots of wheat bait plants grown in soil collected from one of two South Perth samples and all three Esperance samples (Table 4). No Polymyxa spp. were detected in the roots of control plants grown in potting mix. RT-PCR tests detected neither the three soil-borne viruses tested for WSSMV, SBCMV, SBWMV, or furoviruses in general in leaf samples from these wheat bait plants.

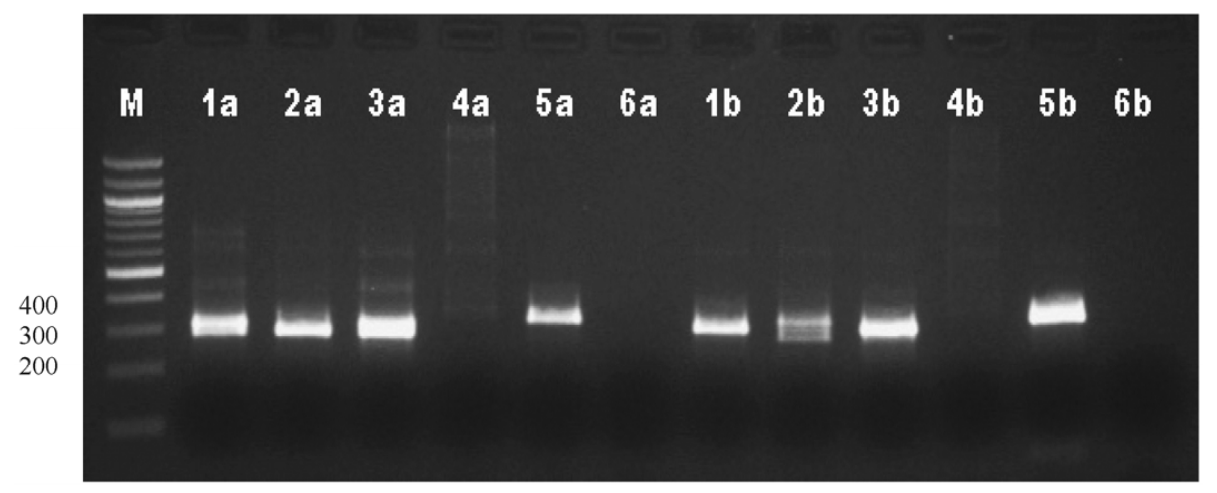

Fig. 2. Agarose gel showing polymerase chain reaction products with a, Polymyxa spp. primers and b, Polymyxa graminis type I and II specific primers. Lanes 1 to 3 : South Perth wheat root samples, lane 4: uninfected wheat roots, lane 5: P. graminis +ve barley roots Qld, lane 6: no template control, M: 100-bp DNA ladder.

Table 2. Polymyxa graminis sequences obtained from Australian cereal root samples

\begin{tabular}{|c|c|c|c|c|c|c|c|}
\hline Isolate & Location & Accession & Primers used & $\begin{array}{l}\text { Sequence } \\
\text { length }(b)\end{array}$ & $\begin{array}{c}\text { Region } \\
\text { included }\end{array}$ & Closest sequence match & $\begin{array}{l}\% \text { Nucleotide } \\
\text { identity }\end{array}$ \\
\hline EspW12 & Esperance & KF657737 & Psp1/Psp2rev & 518 & ITS1 & AMO75823 UK garden soil & 99.7 \\
\hline NorP5B & Northam & KF535917 & Psp1/Psp2rev & 520 & ITS1 & As above & 99.7 \\
\hline NorP5S & Northam & KF535918 & Psp1/Psp2rev & 470 & ITS1 & AM110920 Belgium, rye & 97.1 \\
\hline NorP38 & Northam & KF535919 & Psp1/Psp2rev & 471 & ITS1 & AM259279 Belgium, barley & 99.8 \\
\hline SP2 & South Perth & KF535920 & Pgf2/ITS4 & 493 & ITS 1 and 2 & AJ841287 UK wheat & 99.6 \\
\hline SP1 & South Perth & KF535921 & Psp1/ITS4 & 672 & ITS 1 and 2 & EU244488 Switzerland & 100 \\
\hline QldB & Queensland & KF535922 & Psp1/ITS4 & 695 & ITS 1 and 2 & $\begin{array}{l}\text { HE5 } 65477 \text { Burkina Faso, } \\
\text { Sorghum }\end{array}$ & 99.8 \\
\hline
\end{tabular}




\section{Discussion}

In this study, presence of $P$. graminis was confirmed for the first time in southwest Australia, and for the second time in Australia as a whole. It was found by PCR in roots of 11 wheat plants from low-lying areas within wheat fields or field plots at three widely dispersed locations in southwest Australia, and characteristic $P$. graminis sporosori were observed microscopically in stained root samples. $P$. graminis was also detected by PCR in roots of wheat bait-plants grown in soil samples from two of these locations. Ribosomal DNA sequencing of root samples from the field in southwest Australia revealed the presence of genetically distinct $P$. graminis isolates with wide nt diversity across their internal transcribed spacer regions. Phylogenetic analysis of $P$. graminis ITS rDNA sequences produced trees similar to those previously reported $(30,39)$, but with the inclusion of seven new Australian iso-

Table 3. Details of Polymyxa graminis isolates with rDNA internal transcribed spacer region sequences used to establish sequence identities and for phylogenetic analysis

\begin{tabular}{|c|c|c|c|c|}
\hline Accession number & Isolate name & Geographical origin & Isolation source & Reference \\
\hline AJ010424 & Meta & Colombia & Rice & 24 \\
\hline AJ311572 & B1 & Belgium & Barley & 18 \\
\hline AJ311573 & $\mathrm{C} 1$ & Canada & Barley & 18 \\
\hline AJ311574 & F11 & France & Barley & 18 \\
\hline AJ311575 & I1-1 & India & Sorghum & 18 \\
\hline AJ311576 & I1-20 & India & Sorghum & 18 \\
\hline AJ311577 & I9 & India & Sorghum & 18 \\
\hline AJ311578 & I10 & India & Pearl millet & 18 \\
\hline AJ311579 & P1 & Pakistan & Sorghum & 18 \\
\hline AJ311580 & S6 & Senegal & Pearl millet & 18 \\
\hline AJ841287 & Kent & UK & Wheat & 39 \\
\hline AM075820 & Afr2 & Cote d'Ivoire & Rice & 39 \\
\hline AM075823 & Garden & UK & Wheat & 39 \\
\hline AM110920 & C13Sh & Belgium & Rye & None \\
\hline AM259275 & C14Oto & Belgium & Barley & 34 \\
\hline AM259276 & $\mathrm{C} 160 \mathrm{c}$ & Belgium & Barley & 34 \\
\hline AM259277 & $\mathrm{C} 11 \mathrm{Fc}$ & Belgium & Wheat & 34 \\
\hline AM259278 & $\mathrm{C} 12 \mathrm{Fs}$ & Belgium & Wheat & 34 \\
\hline AM259279 & Oto4 & Belgium & Barley & 34 \\
\hline AM259280 & Oc6 & Belgium & Barley & 34 \\
\hline AM259281 & Oc12 & Belgium & Barley & 34 \\
\hline AM259282 & $\mathrm{Fc} 17$ & Belgium & Wheat & 34 \\
\hline AM259283 & $\mathrm{Fc} 18$ & Belgium & Wheat & 34 \\
\hline AM259284 & Ff24 & Belgium & Wheat & 34 \\
\hline EU244487 & $\mathrm{Sg}$ & Switzerland & Unknown & None \\
\hline EU244488 & $\mathrm{Ag}$ & Switzerland & Unknown & None \\
\hline FN393966 & CoWob11 & UK & Arabidopsis & 29 \\
\hline FN393967 & LeWil7 & UK & Arabidopsis & 29 \\
\hline FN393968 & LeWob8 & UK & Arabidopsis & 29 \\
\hline FN393969 & CoWil1 & UK & Arabidopsis & 29 \\
\hline FN393970 & CoWil7 & UK & Arabidopsis & 29 \\
\hline FN393971 & CoWob3 & UK & Arabidopsis & 29 \\
\hline FN393972 & Cowob10 & UK & Arabidopsis & 29 \\
\hline FN393973 & LeWob34 & UK & Arabidopsis & 29 \\
\hline FN393974 & LeWi13 & UK & Arabidopsis & 29 \\
\hline FN393975 & CoWob29 & UK & Arabidopsis & 29 \\
\hline GQ892044 & Austria & Austria & Poa & 25 \\
\hline HE565475 & Se-141 & Senegal & Unknown & 19 \\
\hline HE565476 & BF-207 & Burkina Faso & Sorghum & 19 \\
\hline HE565477 & BF-209 & Burkina Faso & Sorghum & 19 \\
\hline HE860044 & Wob25 & UK & Soil & 30 \\
\hline HE860045 & Sch1 & Germany & Barley & 30 \\
\hline HE860046 & Sch2 & Germany & Barley & 30 \\
\hline HE860047 & 87Sum6 & USA & Wheat & 30 \\
\hline HE860048 & 87Sum8 & USA & Wheat & 30 \\
\hline HE860049 & 108Sum5 & USA & Wheat & 30 \\
\hline HE860050 & 108Sum18 & USA & Wheat & 30 \\
\hline HE860051 & 3Ger1 & Germany & Rye & 30 \\
\hline HE860052 & 3Ger2 & Germany & Rye & 30 \\
\hline HE860053 & 7Ger12 & Germany & Rye & 30 \\
\hline HE860054 & Ken21 & UK & Soil & 30 \\
\hline HE860055 & Ken5 & UK & Soil & 30 \\
\hline HQ378505 & Czech & Czech & Barley & 14 \\
\hline KF657737 & EspW12B & Australia & Wheat & This study \\
\hline KF535917 & NorP5B & Australia & Wheat & This study \\
\hline KF535918 & NorP5S & Australia & Wheat & This study \\
\hline KF535919 & NorP38 & Australia & Wheat & This study \\
\hline KF535920 & SP2 & Australia & Wheat & This study \\
\hline KF535921 & SP1 & Australia & Wheat & This study \\
\hline KF535922 & QldB & Australia & Barley & This study \\
\hline Y12824 & F1 & UK & Barley & 36 \\
\hline Y12825 & I1-229 & India & Sorghum & 36 \\
\hline Y12826 & F51 & UK & Oat & 36 \\
\hline Y12827 & F67 P. betae & Netherlands & Sugar beet & 36 \\
\hline
\end{tabular}


lates revealing even greater sequence diversity. Six clades with strong bootstrap support could be distinguished on both trees, clades I to $\mathrm{V}$ corresponding to the five recognized ribotypes. All temperate forms of $P$. graminis f. sp. temperata (ribotype Ia and Ib) and f. sp. tepida (ribotype IIa and IIb) were identified among the southwest Australian isolates, sometimes within the same sample. In addition, inclusion of an isolate from Queensland, northeast Australia revealed presence of a new sequence group proposed in this study, ribotype VI.

No virus particles were observed by electron microscopy in leaf samples from the Queensland barley crop where P. graminis was first detected in Australia (33). In this study, RT-PCR testing for
WSSMV, SBCMV, and SBWMV, and for furoviruses in general, was undertaken on (i) leaf survey samples collected at random from 39 wheat crops growing at 27 widely dispersed locations in the southwest Australian grainbelt; (ii) 21 individual wheat plant samples, which included 14 with Polymyxa spp. in their roots, collected from low-lying areas within 21 fields at 10 locations in the grainbelt and one irrigated Metropolitan field plot location; and (iii) samples from bait plants grown in five soil samples from $P$. graminis infested locations, three from the grainbelt and two from Metropolitan field plots. However, no viruses were detected in any of these samples. More extensive sampling of wheat crops, especially targeting those growing in high rainfall grainbelt zones prone

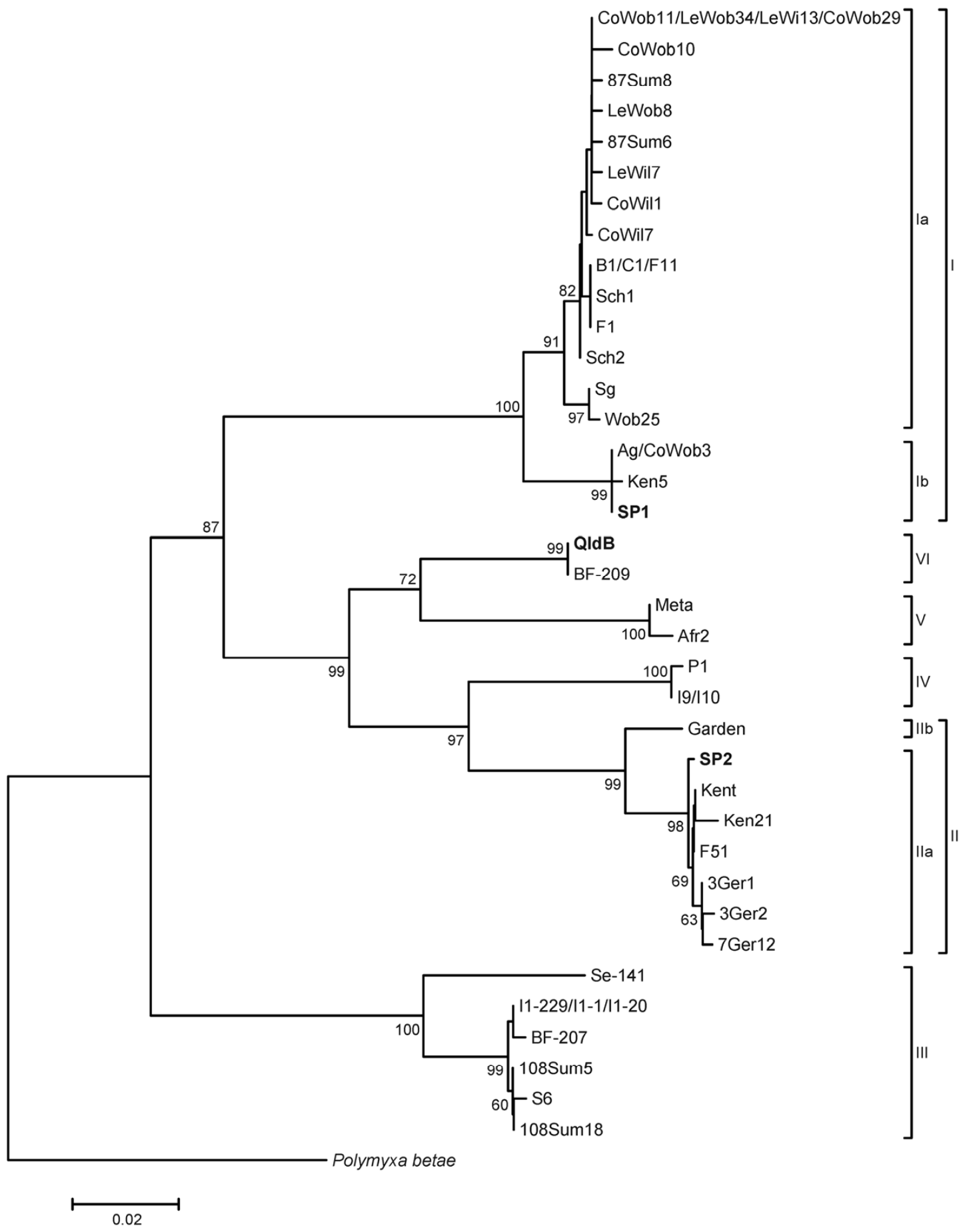

Fig. 3. Neighbor-joining relationship tree for the rDNA internal transcribed spacer nucleotide sequences of 46 Polymyxa graminis isolates from GenBank, and three from this study (shown in bold). A Polymyxa betae sequence is included as an outgroup. Details of sequences are given in Table 3. Tree branches were bootstrapped with 10,000 replicates. Numbers at nodes indicate bootstrap scores $>60 \%$. Evolutionary distances were computed using the Maximum Composite Likelihood Method. Scale bar represents a genetic distance of 0.02 for horizontal branch length. The phylogenetic tree was generated using MEGA version 5 (32). 
to water-logging, is warranted before any conclusions can be drawn about the presence or absence of soil-borne wheat viruses in the region.

The six sequenced southwest Australian $P$. graminis isolates shared sequence identities with temperate isolates belonging to ribotypes I and II, found in wheat, barley, rye, and garden soil in Europe. These ribotypes are associated with transmission of SBCMV, SBWMV, and WSSMV. Moreover, isolate SP1 closely resembled the short 258-bp $P$. graminis isolate cv. 1393-06 sequence (accession no. EU826169) found associated with SBWMV in wheat in New Zealand (16), as both sequences matched ribotype Ib Swiss isolate Ag (accession no. EU244488), and UK isolate CoWob3 (accession no. FN393971). The sequence of the Queensland isolate from barley was very different, being almost identical to a tropical $P$. graminis isolate from sorghum in Burkina Faso (19).

Based on PCR data, Thompson et al. (33) had suggested previously that the Queensland barley samples, which were all from the

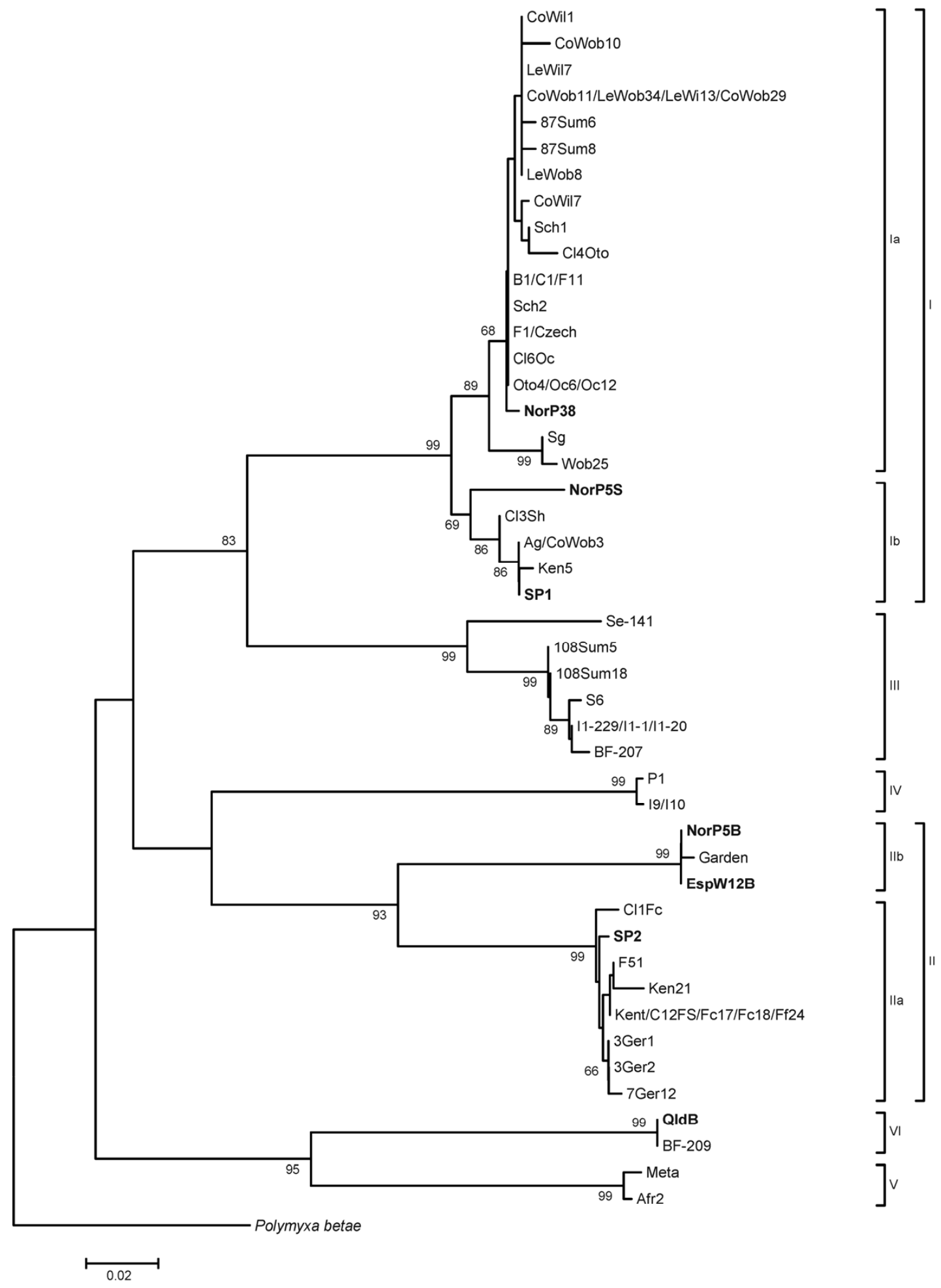

Fig. 4. Neighbor-joining relationship tree for the partial rDNA internal transcribed spacer nucleotide sequences of 62 Polymyxa graminis isolates from GenBank, and seven from this study (shown in bold). A Polymyxa betae sequence is included as an outgroup. Details of sequences are given in Table 3 . Tree branches were bootstrapped with 10,000 replicates. Numbers at nodes indicate bootstrap scores $>60 \%$. Evolutionary distances were computed using the Maximum Composite Likelihood Method. Scale bar represents a genetic distance of 0.02 for horizontal branch length. The phylogenetic tree was generated using MEGA 5 (32) 


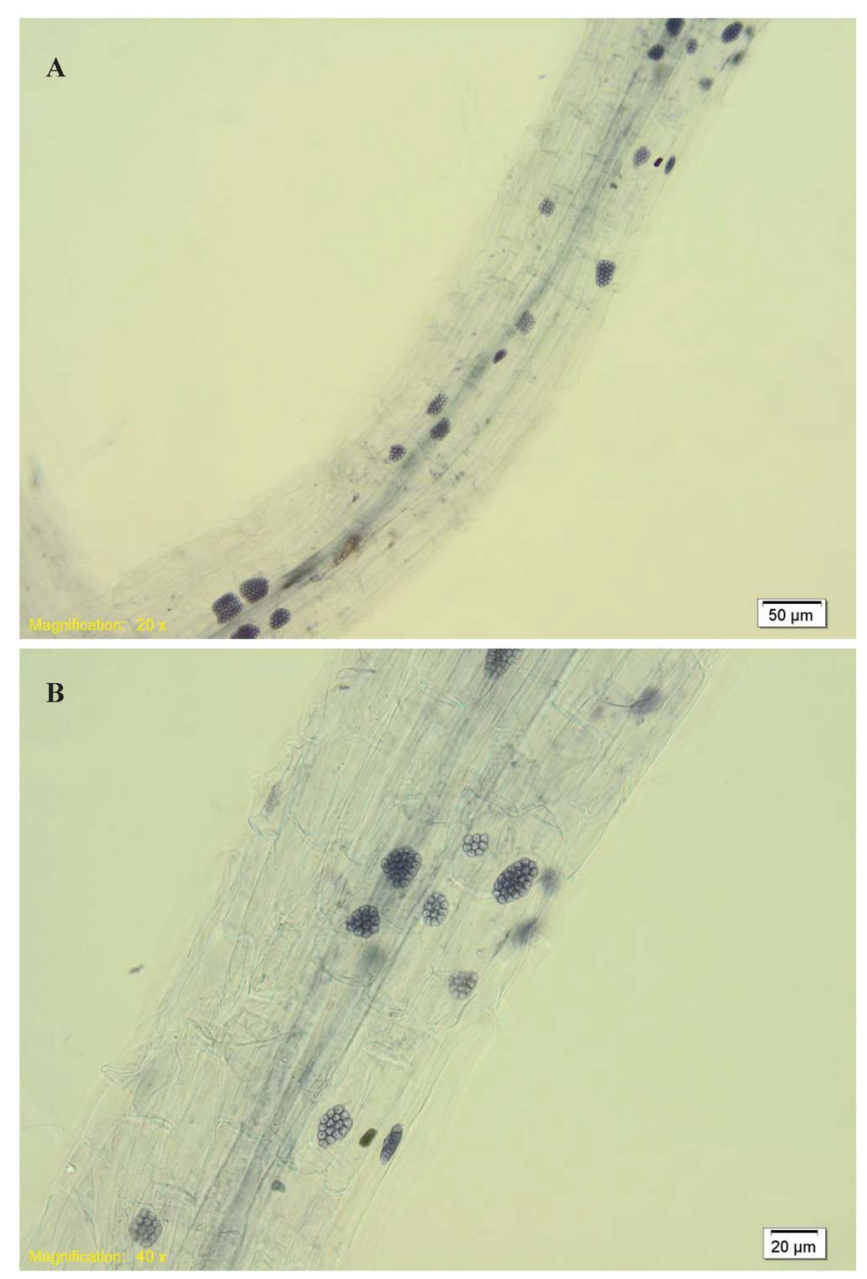

Fig. 5. Photomicrographs of sporsori of Polymxa graminis in roots of wheat cv. Benu from Northam, WA. Roots cleared and stained with trypan blue and observed at $\mathrm{A}, \times 200$ and $\mathrm{B}, \times 400$ magnifications.

same location, contained $P$. graminis ribotype II, but noted that there might have also been a second ribotype present, possibly tropical ribotype III. According to PCR results from southwest Australia, three samples from Esperance and one from Kulin contained $P$. graminis ribotype III, but this was not confirmed by sequencing, in which only a partial sequence from the Kulin sample was obtained. Moreover, the sequence obtained for isolate $\mathrm{SP} 1$, which placed it in ribotype Ib, had some sequence variation in the region where primer Pgfwd2 binds, so this might have prevented its detection by the ribotype I and II specific PCR primers. In an assessment based on PCR alone, such a result would have incorrectly indicated it was ribotype III instead of ribotype Ib. The samples from Esperance and Kulin might therefore have contained similar ribotype Ib isolates rather than ribotype III. Further studies are required on new samples from northeast Australia to establish whether $P$. graminis ribotypes I, II, III, and other ribotypes are present there, and in southwest Australia to establish whether ribotype III is present. Smith et al. (30) recently reported the presence of $P$. graminis ribotype III in California which has a Mediterranean-type climate like that of southwest Australia, so its possible presence in southwest Australia or subtropical northeast Australia would seem consistent with the U.S. experience.

P. graminis isolates found around the world show a high degree of genetic diversity (30). In this study, with some of the wheat root samples, PCR tests with the two primer pairs gave double bands or two different-sized bands, which might indicate the presence of more than one $P$. graminis ribotype or, possibly, of another Polymyxa species. One partial sequence from Kulin and another from
Table 4. Detection of Polymyxa graminis by polymerase chain reaction (PCR) in the roots of wheat bait plants grown in soil collected from locations where $P$. graminis was found ${ }^{\mathrm{a}}$

\begin{tabular}{llcc}
\hline & Collection & \multicolumn{1}{c}{$\begin{array}{c}\text { Number of plants positive with } \\
\text { primer sets }\end{array}$} \\
\cline { 3 - 4 } Soil sample & location & Pxfwd1/Pxrev7 & Pgfwd2/Pxrev7 \\
\hline SP 22 & South Perth & $0 / 4$ & $0 / 4$ \\
SP 28 & South Perth & $2 / 4$ & $2 / 4$ \\
E2 & Esperance & $4 / 4$ & $2 / 4$ \\
GG & Esperance & $3 / 4$ & $0 / 4$ \\
W12 & Esperance & $3 / 4$ & $3 / 4$ \\
Potting mix control & $\ldots$ & $0 / 4$ & $0 / 4$ \\
\hline
\end{tabular}

a Four wheat plants were planted per pot, then tested individually by PCR.

Esperance shared some homology with other $P$. graminis sequences, but were too short to identify them. When a second PCR band produced from Queensland samples with primers Psp1/Psp2rev was sequenced, it was more closely related to $P$. betae. Because Polymyxa spp. are obligate biotrophs and can only be maintained in the roots of plants, it is often difficult to obtain high quality DNA extracts for sequencing that are sufficiently free from host DNA and other root organisms, especially from field samples. In the future, to help overcome problems with sequencing samples containing different Polymyxa ribotypes or species, propagation of single spore cultures on host plants in semisterile cultures (2) or cloning of PCR products would be preferable.

Agriculture only commenced within the Australian continent 226 years ago following European colonization, and many crop pathogens found elsewhere in the world are absent. However, the finding of (i) $P$. graminis isolates belonging to two different ribotypes, and two different subclades within each of them, in a small-scale survey in southwest Australia, and (ii) a distinct $P$. graminis ribotype in northeast Australia, would suggest that there have already been multiple introductions to the Australian continent. A widespread survey involving many more samples, locations, and regions would be required to establish whether $P$. graminis is widespread in the soils of Australia's different regional grainbelts. IPVC is seedborne in millet and peanut (27). Also, there is evidence that SBCMV may be seedborne in wheat (7), and also spread through surface contamination of seeds with viruliferous $P$. graminis resting spores so soil-borne viruses are likely to be introduced in this way to new regions. Assuming that this has not occurred already or remains undetected as yet, if soil-borne wheat viruses were to arrive in Australia via viruliferous resting spore contaminated imported wheat seed or infested soil material, they could become a widespread threat to cereal production, especially in high rainfall zones, as the vector is already established. Moreover, once soil-borne viruses are established in an agricultural area, they cannot be eradicated from the soil due to the resilience and persistence of viruliferous $P$. graminis resting spores. Chemical control is not effective or environmentally acceptable, and the principal way to control such virus diseases effectively once they become established is through development of virus-resistant cultivars (15). There are cereal breeding programs breeding for resistance to soil-borne viruses transmitted by $P$. graminis in many other countries, but the molecular diversity of virus strains is providing an ongoing challenge to their effectiveness (15). No such cereal breeding for resistance to soil-borne viruses has been undertaken in Australia, but pre-emptive breeding for this purpose should be considered as a precautionary measure, especially for wheat because of its significance as the country's most important and largest agricultural export commodity.

\section{Acknowledgments}

This research was funded by the Grains Research and Development Corporation (GRDC) project UM00041. We thank Brenda Coutts and Monica Kehoe for collection of field and soil samples in southwest Australia, and John Thompson and Kirsty Owen for kindly supplying P. graminis root samples from Queensland. 


\section{Literature Cited}

1. Adams, M. J., and Jacquier, C. 1994. Infection of cereals and grasses by isolates of Polymyxa graminis (Plasmodiophorales). Ann. Appl. Biol. 125:53-60.

2. Adams, M. J., Swaby, A. G., and Macfarlane, I. 1986. The susceptibility of barley cultivars to Barley yellow mosaic virus (BaYMV) and its fungal vector, Polymyxa graminis. Ann. Appl. Biol. 109:561-572.

3. APPD (Australian Plant Pest Database) 2005. http://www.planthealth australia.com.au/

4. Barr, D. J. S. 1979. Morphology and host range of Polymyxa graminis, Polymyxa betae and Ligniera pilorum from Ontario and some other areas. Can. J. Plant. Pathol. 1:85-94.

5. Barr, D. J. S. 1988. Zoosporic plant parasites as fungal vectors of viruses: Taxonomy and life cycles of species involved. Pages 123-137 in: Developments in Applied Biology 2: Viruses with Fungal Vectors. J. I. Cooper and M. J. C. Asher, eds. Association of Applied Biologists, Wellesbourne, Warwick, UK.

6. Braselton, J. P. 1995. Current status of the plasmodiophorids. Crit. Rev. Microbiol. 21:263-265.

7. Budge, G. E., Loram, J., Donovan, G., and Boonham, N. 2008. RNA2 of Soil-borne cereal mosaic virus is detectable in plants of winter wheat grown from infected seeds. Eur. J. Plant Pathol. 120:97-102.

8. Clover, G. R. G., Ratti, C., and Henry, C. M. 2001. Molecular characterization and detection of European isolates of Soil-borne wheat mosaic virus. Plant Pathol. 50:761-767.

9. Deb, M., and Anderson, J. M. 2008. Development of a multiplexed PCR detection method for Barley and Cereal yellow dwarf viruses, Wheat spindle streak virus, Wheat streak mosaic virus and Soil-borne wheat mosaic virus. J. Virol. Methods 148:17-24.

10. Dick, M. W. 2001. Straminipilous Fungi: Systematics of the Peronosporomycetes including accounts of the marine straminipilous Protists, the Plasmodiophorids and Similar Organisms. Kluwer Academic Publishers, Dordrecht, the Netherlands.

11. Dieryck, B., Weyns, J., Doucet, D., Bragard, C., and Lègreve, A. 2011. Acquisition and transmission of Peanut clump virus by Polymyxa graminis on cereal species. Phytopathology 101:1149-1158.

12. Jones, R. 2004. A national diagnostic protocol for soil-borne viruses of wheat. Department of Agriculture, State of Western Australia.

13. Kanyuka, K., Ward, E., and Adams, M. J. 2003. Polymyxa graminis and the cereal viruses it transmits: A research challenge. Mol. Plant. Pathol. 4:393406.

14. Ketta, H., Zouhar, M., and Rysanek, P. 2011. First report of Polymyxa graminis f. sp. temperata, a vector of soil-borne cereal viruses in the Czech Republic. Plant Dis. 95:353.

15. Kühne, T. 2009. Soil-borne viruses affecting cereals - Known for long but still a threat. Virus Res. 141:174-183.

16. Lebas, B. S. M., Ochoa-Corona, F. M., Elliott, D. R., Tang, J., Blouin, A. G., Timudo, O. E., Ganev, S., and Alexander, B. J. R. 2009. Investigation of an outbreak of Soil-borne wheat mosaic virus in New Zealand. Australas. Plant Pathol. 38:85-90.

17. Ledingham, G. A. 1939. Studies on Polymyxa graminis n. gen. n. sp., a plasmodiophoraceous root parasite of wheat. Can. J. Res. C. 17:38-51.

18. Legrève, A., Delfosse, P., and Maraite, H. 2002. Phylogenetic analysis of Polymyxa species based on nuclear 5.8S and internal transcribed spacers ribosomal DNA sequences. Mycol. Res. 106:138-147.

19. Legrève, A., Delfosse, P., Ribonnet, L., Paridaens, A. M., Lurkin, R., and Maraite, H. 2005. Diversity of Polymyxa graminis associated with cereals in West Africa. Parasitica 61:5-10.

20. Legrève, A., Delfosse, P., Van Hese, V., Bragard, C., and Maraite, H. 2003. Broad-spectrum detection of Polymyxa species and form species by polymerase chain reaction. Pages 40-43 in: Proc. 5th Sympos. Int. Working Group Plant Viruses with Fungal Vectors, Institute of Plant Sciences, Swiss Federal Institute of Technology, Zurich, Switzerland.

21. Legrève, A., Delfosse, P., Vanpee, B., Goffin, A., and Maraite, H. 1998. Differences in temperature requirements between Polymyxa sp. of Indian origin and Polymyxa graminis and Polymyxa betae from temperate areas. Eur. J. Plant Pathol. 104:195-205.

22. Legrève, A., Vanpee, B., Delfosse, P., and Maraite, H. 2000. Host range of tropical and sub-tropical isolates of Polymyxa graminis. Eur. J. Plant Pathol. 106:379-389.

23. Lyons, R., Hammond-Kosack, K. E., and Kanyuka, K. 2008. Identification and characterization of a novel efficient resistance response to the furoviruses SBWMV and SBCMV in barley. Mol. Plant-Microbe Interact. 21:1193-1204.

24. Morales, F. J., Ward, E., Castaño, M., Arroyave, J. A., Lozano, I., and Adams, M. J. 1999. Emergence and partial characterization of Rice stripe necrosis virus and its fungus vector in South America. Eur. J. Plant Pathol. 105:643-650.

25. Neuhauser, S., and Kirchmair, M. 2009. Ligniera junci, a plasmodiophorid re-discovered in roots of Juncus in Austria. Osterr. Z. Pilzkd. 18:141-147.

26. Phillips, J. M., and Hayman, D. S. 1970. Improved procedures for clearing roots and staining parasitic and vesicular-arbuscular mycorrhizal fungi for rapid assessment of infection. Trans. Br. Mycol. Soc. 55:158-161.

27. Reddy, A. S., Hobbs, H. A., Delfosse, P. A., Murthy, K., and Reddy, D. V. R. 1998. Seed Transmission of Indian peanut clump virus (IPCV) in peanut and millets. 82:343-346.

28. Rodoni, B., and Zheng, L. 2010. Enhanced diagnostic platforms for Post Entry Quarantine (PEQ) and market access. Final Report, CRC 40050. Cooperative Research Centre for National Plant Biosecurity, Canberra, Australia.

29. Smith, M. J., Adams, M. J., and Ward, E. 2011. Evidence that Polymyxa species may infect Arabidopsis thaliana. FEMS Microbiol. Lett. 318:35-40.

30. Smith, M. J., Adams, M. J., and Ward, E. 2013. Ribosomal DNA analyses reveal greater sequence variation in Polymyxa species than previously thought and indicate the possibility of new ribotype-host-virus associations. Environ. Microbiol. Rep. 5:143-150.

31. Tamada, T., and Kondo, H. 2013 Biological and genetic diversity of plasmodiophorid-transmitted viruses and their vectors. J. Gen. Plant Pathol. 79:307-320.

32. Tamura, K., Peterson, D., Peterson, N., Stecher, G., Nei, M., and Kumar, S. 2011. MEGA5: Molecular Evolutionary Genetics Analysis using Maximum Likelihood, Evolutionary Distance, and Maximum Parsimony Methods. Mol. Biol. Evol 28:2731-2739.

33. Thompson, J. P., Clewett, T. G., Jennings, R. E., Sheedy, J. G., Owen, K. J., and Persley, D. M. 2011. Detection of Polymyxa graminis in a barley crop in Australia. Australas. Plant Pathol. 40:66-75.

34. Vaïanopoulos, C., Bragard, C., Moreau, V., Maraite, H., and Legrève, A. 2007. Identification and quantification of Polymyxa graminis f. sp. temperata and $P$ graminis f. sp tepida on barley and wheat. Plant Dis. 91:857-864.

35. Vaïanopoulos, C., Legrève, A., Lorca, C., Moreau, V., Steyer, S., Maraite, H., and Bragard, C. 2006. Widespread occurrence of Wheat spindle streak mosaic virus in Belgium. Plant Dis. 90:723-728.

36. Ward, E., and Adams, M. J. 1998. Analysis of ribosomal DNA sequences of Polymyxa species and related fungi and the development of genus- and species-specific PCR primers. Mycol Res. 102:965-974.

37. Ward, E., Adams, M. J., Mutasa, E. S., Collier, C. R., and Asher, M. J. C. 1994. Characterization of Polymyxa species by restriction analysis of PCRamplified ribosomal DNA. Plant Pathol. 43:872-877.

38. Ward, E., Kanyuka, K., Motteram, J., Kornyukhin, D., and Adams, M. J. 2005. The use of conventional and quantitative real-time PCR assays for Polymyxa graminis to examine host plant resistance, inoculum levels and intraspecific variation. New Phytol. 165:875-885.

39. Ward, E., Motteram, J., Kanyuka, K., and Adams, M. J. 2005. The use of PCR methods for Polymyxa graminis to study intraspecific variation, phylogeny and inoculum levels. Pages 103-106 in: 6th Sympos. Int. Working Group Plant Viruses with Fungal Vectors. C. M. Rush, ed. American Society of Sugar Beet Technologists, Bologna, Italy.

40. White, T. J., Bruns, T., Lee, S., and Taylor, J. 1990. Amplification and direct sequencing of fungal ribosomal RNA genes for phylogenetics. Pages 315322 in: PCR Protocols: A Guide to Methods and Applications. M. Innis, D. Gelfand, J. Sninsky, and T. White, eds. Academic Press, San Diego. 